\title{
Segment-based myocardial T1 and T2 mapping at 3T: feasibility and normal values
}

\author{
Florian von Knobelsdorff-Brenkenhoff ${ }^{1,2^{*}}$, Matthias A Dieringer ${ }^{1,2}$, Marcel Prothmann ${ }^{1,2}$, Andreas Greiser ${ }^{3}$, \\ Thoralf Niendorf ${ }^{1,4}$, Jeanette Schulz-Menger ${ }^{1,2}$ \\ From 16th Annual SCMR Scientific Sessions \\ San Francisco, CA, USA. 31 January - 3 February 2013
}

\section{Background}

Myocardial T1 and T2 mapping using cardiovascular magnetic resonance imaging (CMR) is promising to improve disease detection and monitoring. We applied $\mathrm{T} 1$ and T2 mapping at 3T to study the technical feasibility and provide reference values in healthy volunteers.

\section{Methods}

Sixty healthy volunteers ( 30 males / 30 females, 20 in each age group: $20-39$ years, $40-59$ years, $60-80$ years) underwent T1 and T2 mapping of the left ventricle in 3 short axis slices. For T2 maps, 3 single shot steady state free precession (SSFP) images with different T2 preparation times $(0,24,55 \mathrm{~ms})$ were acquired (TE $1.0 \mathrm{~ms}$, TR $2.4 \mathrm{~ms}$, voxel $\left.1.9 \times 1.9 \times 6 \mathrm{~mm}^{3}\right)$. For T1 maps, Modified Look-Locker Inversion Recovery (MOLLI) technique with 11 single shot SSFP images was used before and after injection of gadolinium contrast (pre-contrast: TE $1.0 \mathrm{~ms}$, TR $2.6 \mathrm{~ms}$, voxel size $1.4-1.7 \times 1.4-1.7 \times 6 \mathrm{~mm}^{3}$ ). $\mathrm{T} 1$ and $\mathrm{T} 2$ relaxation times were quantified for each slice and each myocardial segment.

\section{Results}

With T2 maps, $97.7 \%$ of all segments were diagnostic and $2.3 \%$ were excluded (susceptibility artifact, Figure $1 \mathrm{a}$ ). With T1 maps (pre-/post-contrast), 91.6\% / 93.9\% were

diagnostic, while $8.4 \%$ / 6.1\% were excluded $(7.7 \%$ / 3.2\% susceptibility artifact (Figure 1b); 0.7\% / 2.2\% incorrect motion correction; 0\% / 0.7\% mistriggering). Mean T2 times and $95 \%$ tolerance interval were: base: $44.1 \mathrm{~ms}$ (39.3-49-5 ms); middle: $45.1 \mathrm{~ms}$ (39.9-50.1 ms); apex: $46.9 \mathrm{~ms}$ (40.8-53.8 ms). Mean T1 times and 95\% tolerance interval pre- and post-contrast were: Base: 1157.1 $\mathrm{ms}$ (1074.5-1246.0) and $427.3 \mathrm{~ms}$ (363.2-502.7 ms). Middle: $1158.7 \mathrm{~ms}(1074.0-1250.1 \mathrm{~ms})$ and $411.2 \mathrm{~ms}$ (349.9-483.2 ms). Apex: $1180.6 \mathrm{~ms}$ (1073.9-1297.9 ms) and $399.7 \mathrm{~ms}$ (323.0-494.6 ms). The segmental results are depicted in figure 2. Inter- and intra-observer analysis of $\mathrm{T} 2(\mathrm{r}=0.95 ; \mathrm{r}=0.95)$ and $\mathrm{T} 1(\mathrm{r}=0.91 ; \mathrm{r}=0.93)$ demonstrated excellent agreement $(\mathrm{p}<0.0001)$.

\section{Conclusions}

T2 and T1 mapping at 3T was technically feasible, reference values for each myocardial segment are now provided, and observer dependency was low. However, 3T-related susceptibility artifacts and the relatively wide tolerance interval of T2 and T1 times must be considered during interpretation.

\section{Funding}

This project is supported by the Else Kröner-Fresenius Stiftung (Bad Homburg, Germany). 
Figure 1a: T2 Mapping
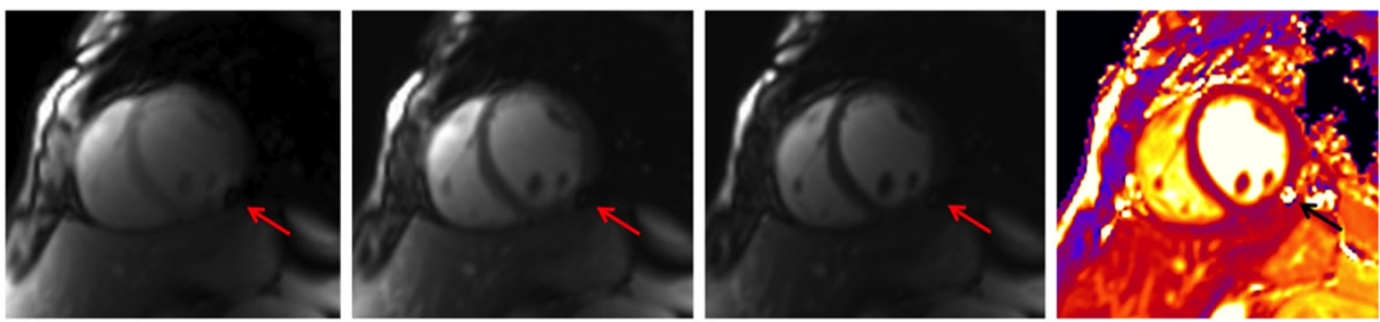

Figure 1b: T1 Mapping
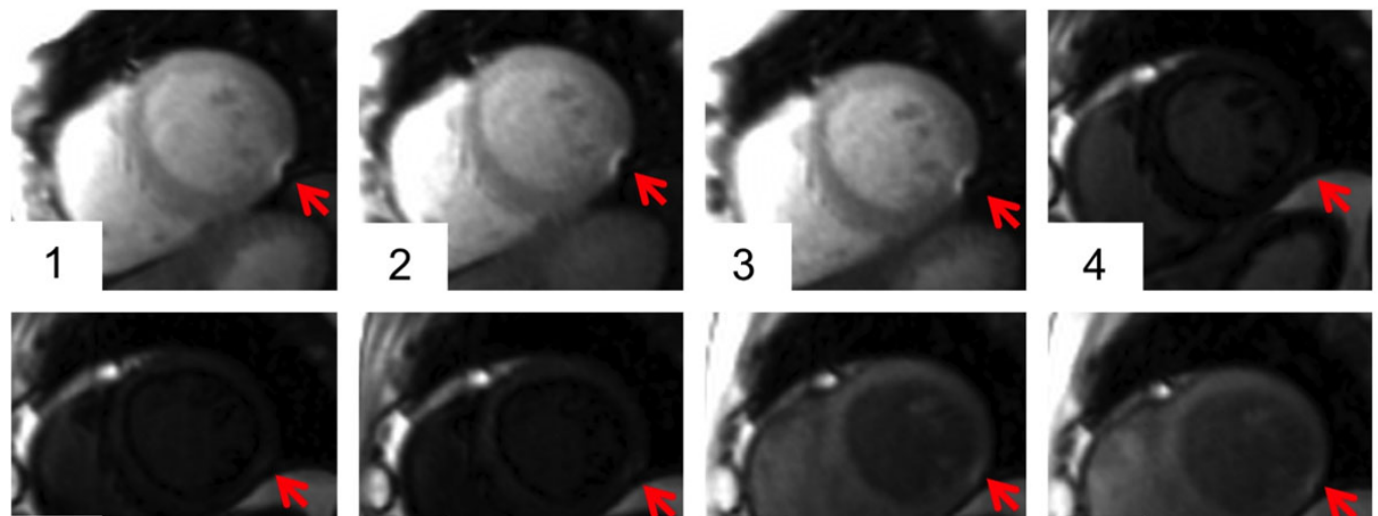

5
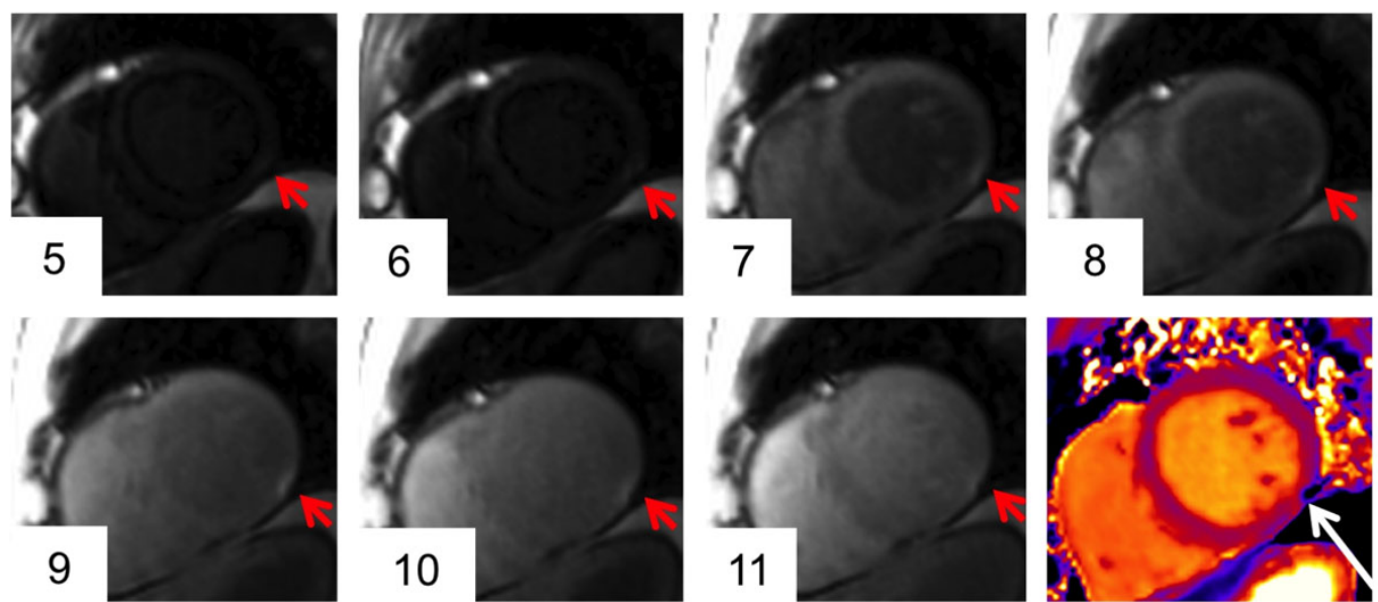

Figure 1 A T2 mapping; three original images and the resulting T2 map with susceptibility artifact in the inferolateral segment. b: T1 mapping; eleven original images and the resulting $\mathrm{T} 1$ map with susceptibility artifact in the inferolateral segment.
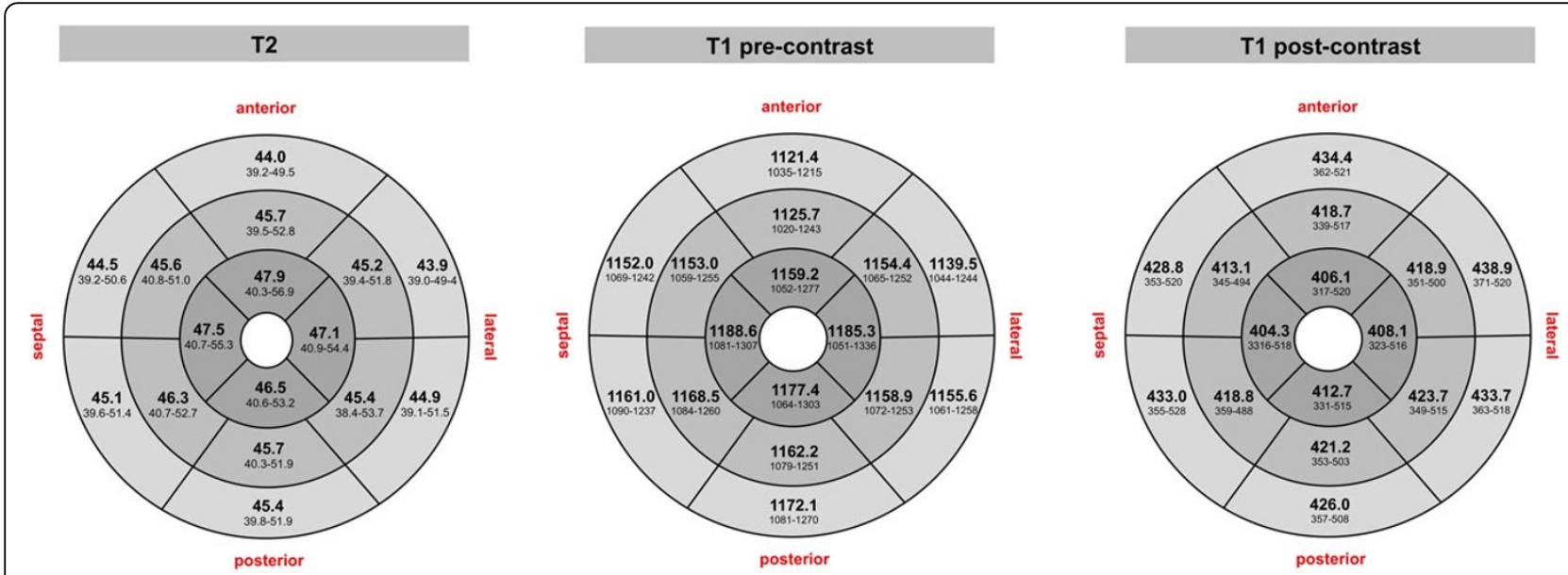

Figure 2 T2 and T1 relaxation times for each myocardial segment (mean, 95\% tolerance interval). 


\section{Author details}

${ }^{1}$ Berlin Ultrahigh Field Facility, Berlin, Germany. ${ }^{2}$ Working Group

Cardiovascular MRI, Experimental and Clinical Research Center (Charite, MDC) and HELIOS Clinics, Berlin, Germany. ${ }^{3}$ Siemens Healthcare, Erlangen,

Germany. ${ }^{4}$ Experimental and Clinical Research Center (Charite, MDC), Berlin,

Germany.

Published: 30 January 2013

doi:10.1186/1532-429X-15-S1-P37

Cite this article as: von Knobelsdorff-Brenkenhoff et al: Segment-based

myocardial T1 and T2 mapping at 3T: feasibility and normal values.

Journal of Cardiovascular Magnetic Resonance 2013 15(Suppl 1):P37.

Submit your next manuscript to BioMed Central and take full advantage of:

- Convenient online submission

- Thorough peer review

- No space constraints or color figure charges

- Immediate publication on acceptance

- Inclusion in PubMed, CAS, Scopus and Google Scholar

- Research which is freely available for redistribution

Submit your manuscript at www.biomedcentral.com/submit 